\title{
A Vivência da Sexualidade de Pessoas que Vivem com HIV/Aids
}

\author{
Amanda Araújo Malta de Sá ${ }^{1}$ \\ ${ }^{1}$ Hospital Estadual de Urgências da Região Noroeste de \\ Goiânia Governador Otávio Lage de Siqueira, Goiânia, \\ GO, Brasil.
}

Cristina Vianna Moreira dos Santos ${ }^{2}$

${ }^{2}$ Universidade Federal do Tocantins, TO, Brasil.

Resumo: O Vírus da Imunodeficiência Humana (HIV), responsável pela Síndrome da Imunodeficiência Adquirida (aids), vem ocupando lugar de destaque dentre as mais temidas patologias dos tempos atuais e representa um sério problema de saúde pública, considerada epidemia global, com rápida disseminação e agravamento. Pesquisas apontam que a qualidade de vida de pessoas soropositivas é afetada principalmente no domínio da atividade sexual, o que pode estar relacionado a várias dificuldades, como compartilhar o diagnóstico, medo de perder o parceiro, conflitos, mágoas e ressentimentos que podem estar envolvidos na aquisição do HIV. Sendo assim, esta pesquisa objetivou investigar quais as principais dificuldades nos relacionamentos amorosos e/ou sexuais de sujeitos soropositivos e quais os mecanismos de enfrentamento mais empregados por eles. Foi realizada uma pesquisa descritiva, com base na experiência de uma residente de Psicologia de um hospital de referência no tratamento a pessoas que convivem com o HIV. Fez-se uso do método fenomenológico, para realizar e analisar entrevistas semiestruturadas, gravadas e transcritas, que enfocaram a vivência dos fenômenos e experiências. Os resultados confirmaram a existência do impacto negativo do diagnóstico de HIV nos relacionamentos amorosos e/ou sexuais conforme descrito na literatura. Apontaram, ainda, para diversas formas de enfrentamento utilizadas pelos sujeitos soropositivos.

Palavras-chave: HIV/aids, Sexualidade, Afetividade.

\section{Sexual Experience of People Living with HIV/AIDS}

\begin{abstract}
The Human Immunodeficiency Virus (HIV), which is responsible for the Acquired Immunodeficiency Syndrome (AIDS), has been prominent among the most feared pathologies in current times and represents a serious public health problem, considered a global epidemic, with rapid spread and aggravation. Surveys indicate that the quality of life of people with HIV is mainly affected in the field of sexual activity, which may be related to several difficulties, such as sharing the diagnosis, fear of losing the partner, conflicts, hurt and resentment that may be involved in the acquisition of the virus. Therefore, this research aimed to investigate the main difficulties in the love and/or sexual relationships of HIV positive subjects and the coping mechanisms that are used the most by them. It was a descriptive research, based on the experience of a Psychology resident of a referral hospital in the treatment of people living with HIV. The phenomenological method was used to perform and analyze semi-structured, recorded and transcribed interviews that focused on the experience of the phenomena and experiences. The results confirmed the existence of a negative impact of HIV diagnosis on sexual and/or love relationships as described in the literature. They also pointed to several forms of coping used by HIV positive subjects.
\end{abstract}

Keywords: HIV/AIDS, Sexuality, Affectivity. 


\title{
La Vivencia de la Sexualidad de las Personas que Viven con el VIH/SIDA
}

\begin{abstract}
Resumen: El Virus de la Inmunodeficiencia Humana (VIH), responsable del Síndrome de Inmunodeficiencia Adquirida (SIDA), viene ocupando un lugar destacado entre las más temidas patologías de los tiempos actuales y representa un serio problema de salud pública, considerada epidemia global, con rápida diseminación y agravamiento. Las investigaciones apuntan que la calidad de vida de las personas seropositivas se ve afectada principalmente en el ámbito de la actividad sexual, lo que puede estar relacionado con varias dificultades, como compartir el diagnóstico, miedo a perder al compañero, conflictos, dolor y resentimientos que pueden estar involucrados en la adquisición del VIH. Siendo así, esta investigación objetivó investigar cuáles son las principales dificultades en las relaciones amorosas y/o sexuales de sujetos seropositivos y cuáles los mecanismos de enfrentamiento más empleados por ellos. Se realizó una investigación descriptiva, con base en la experiencia de una residente de Psicología de un hospital de referencia en el tratamiento a personas que conviven con el VIH.. Se hizo uso del método fenomenológico, para realizar y analizar entrevistas semiestructuradas, grabadas y transcritas, que enfocaron la vivencia de los fenómenos y experiencias. Los resultados confirmaron la existencia del impacto negativo del diagnóstico de VIH en las relaciones amorosas y/o sexuales según lo descrito en la literatura. Se señalaron, además, para diversas formas de enfrentamiento utilizadas por los sujetos seropositivos.
\end{abstract}

Palabras clave: VIH/SIDA, Sexualidad, Afectividad.

OVírus da Imunodeficiência Humana (HIV), responsável pela Síndrome da Imunodeficiência Adquirida (aids), vem ocupando lugar de destaque dentre as mais temidas patologias dos tempos atuais (Gomes, Silva, \& Oliveira, 2011). O HIV ataca o sistema imunológico do organismo, que se torna vulnerável a um conjunto de infecções oportunistas potencialmente mortais, o que caracteriza a aids (ONUSIDA, 2004). De acordo com o Programa Conjunto das Nações Unidas sobre o VIH/SIDA - ONUSIDA (2016), estima-se que, até o ano de 2015, 36.700.000 pessoas foram acometidas por este vírus no mundo. Esta patologia representa um sério problema de saúde pública e pode ser considerada epidemia global, com rápida disseminação e agravamento (Gomes et al., 2011).

As principais formas de transmissão do HIV são por vias: sexual, sanguínea (em receptores de sangue ou hemoderivados e em usuários de drogas injetáveis), vertical (da mãe para o filho, durante a gestação, parto ou aleitamento) e ocupacional (administração e infecção através de perfurocortantes). Dentre elas, a transmissão sexual é considerada pela Organização Mundial de Saúde (OMS) como a mais comum em todo mundo (Brasil, 2002a).

Como estratégias no combate ao HIV, os dois grandes enfoques são a prevenção e o tratamento. As principais estratégias de prevenção envolvem o uso de preservativos, $\mathrm{o}$ uso de agulhas e seringas esterilizadas ou descartáveis, o controle do sangue e derivados, a adoção de cuidados na exposição ocupacional a material biológico e o manejo adequado das outras doenças sexualmente transmissíveis - DSTs (Brasil, 2002b). Para tratar pessoas infectadas com o vírus institui-se o uso regular e contínuo da terapia antirretroviral (TARV), cujo objetivo é diminuir sua morbidade e mortalidade, melhorando a qualidade e a expectativa de vida das pessoas que vivem com HIV/aids, já que meios para a cura ainda não foram descobertos (Brasil, 2015).

A partir do emprego da TARV torna-se fundamental discutir a qualidade de vida dos sujeitos soropositivos, que têm que conviver com uma doença crônica e com um tratamento contínuo e imprescindível. Além disso, torna-se um grande desafio para esses sujeitos lidar com o preconceito e a discriminação (Gaspar et al., 2011), associados com a própria descoberta do HIV, já que no início da epidemia relacionaram o vírus aos homossexuais, hemofílicos, haitianos, usuários de drogas e profissionais do sexo, o que tornou a patologia extremamente estigmatizante. Por este motivo há ainda a tendência em associar a infecção pelo HIV a esses grupos. Sendo assim, o medo em ser julgado leva os sujeitos infectados, muitas vezes, a ocultarem 
o diagnóstico como estratégia para minimizar o seu impacto social (Gomes et al., 2011).

Como crítica à ideia de grupo de risco, surgiu o conceito de "comportamento de risco", instituído com o objetivo de desconstruir a ideia de que alguns grupos têm condutas que os expõem ao HIV. O conceito de comportamento de risco veio para universalizar a preocupação com a aids e amenizar seu estigma, buscando estimular o envolvimento ativo das pessoas com a prevenção (Ayres, Calazans, Saletti Filho, \& França-Júnior, 2006). Entretanto, apesar de proporcionar avanços, essa conceituação traz consigo uma limitação: propicia a culpabilização individual, o que leva as pessoas infectadas a atribuírem, muitas vezes, a si mesmas a responsabilidade pela infecção ou pela falha nos esforços de prevenção, desconsiderando, assim, a dimensão social envolvida (Ayres et al., 2006).

A prevenção a comportamentos de risco não depende somente das pessoas, mas de aspectos como: acesso a meios de comunicação, escolarização, disponibilidade de recursos materiais, poder de influenciar decisões políticas, possibilidade de enfrentar barreiras culturais, estar livre de coerções violentas ou poder defender-se delas. Além disso, a vida das pessoas nas sociedades está sempre mediada pelas diversas instituições sociais como família, escolas e serviços de saúde que podem, ou não, fornecer recursos sociais para que a população não se exponha ao HIV e se proteja de seus danos. Para tanto, é necessário que existam esforços institucionais na direção de atenuar as condições socialmente dadas de vulnerabilidade e a perpetuação das situações de risco (Ayres et al., 2006). Neste trabalho optou-se por considerar como ponto de partida para a discussão da problemática "vivência da infecção pelo HIV/aids" o conceito de "comportamento de risco", concebido sob perspectiva sócio-histórica, produto das relações sociais estabelecidas em um determinado modo de produção e contexto político e cultural.

Quando o diagnóstico positivo para HIV já é uma realidade, tornam-se necessárias políticas públicas de inclusão social que favoreçam melhores condições de vida e propiciem o alcance da cidadania. O diagnóstico de infecção pelo HIV modifica as expectativas do sujeito em relação a si próprio e ao meio em que vive. A cronicidade da patologia repercute no âmbito pessoal e social, podendo comprometer as relações interpessoais e a autoestima. Além disso, são necessárias mudanças no estilo de vida, que envolvem a adaptação ao tratamento (Reis, Santos, Dantas, \& Gir, 2011).
Além das dificuldades vivenciadas por sujeitos soropositivos, estudos investigam os mecanismos de enfrentamento comumente empregados por pessoas que convivem com o HIV. Como estratégias de enfrentamento compreende-se o conjunto de esforços cognitivos e comportamentais usados para lidar com situações de estresse, sobrecarga ou cobrança excessiva de seus recursos pessoais (Lazarus, \& Folkman, 1984). Pode-se dividir os recursos de enfrentamento em duas classificações: focalizados na emoção e focalizados no problema, os primeiros relacionados ao manejo dos sentimentos, enquanto os que focalizam o problema envolvem o esforço em mudar a situação causadora do estresse, externamente (procurando ajuda, resolvendo a situação) ou internamente (reestruturando o pensamento) (Carvalho, 2009).

No caso das pessoas que lidam com o HIV/aids, diversas são as formas de enfrentamento. Para enfrentar dificuldades como negação, sintomas depressivos e não-aceitação, há uma prevalência nas estratégias focalizadas na emoção. Já quando se busca apoio social para lidar com a soropositividade, prevalecem as estratégias focalizadas no problema (Carvalho, 2009).

Pesquisas apontam que a qualidade de vida de pessoas soropositivas é afetada principalmente no domínio da atividade sexual. Isto pode estar relacionado a várias dificuldades, como conviver com o HIV/ aids, compartilhar o diagnóstico, medo de perder o parceiro pelo adoecimento e pelos conflitos, mágoas e ressentimentos que podem estar envolvidos na aquisição do HIV (Reis et al., 2011).

De acordo com o Portal da Juventude (2015), sexualidade é uma energia que nos motiva a procurar amor, contato, ternura e intimidade; que se integra ao modo como nos sentimos, movemos, tocamos e somos tocados; é ser sensual e ao mesmo tempo sexual; influencia pensamentos, sentimentos, ações e interações, assim como a nossa saúde física e mental. A sexualidade interfere nos aspectos social e psicológico, ao longo da nossa trajetória de vida, simultaneamente ao desenvolvimento e crescimento do sujeito (Gir, Nogueira, \& Pelá, 2000).

Durante muito tempo, a sexualidade foi entendida apenas como uma necessidade instintiva do corpo, mais especificamente do corpo do homem, já que à mulher ficava reservada uma posição passiva nos relacionamentos sexuais, cujo papel seria cumprir uma função prioritariamente reprodutiva. Entretanto, ao considerar a sexualidade como instintiva à 
natureza, supõe-se que todas as pessoas vivem sua sexualidade de maneira igual e universal, com o fim de servir à reprodução da espécie e ao extravasamento de uma pulsão de ordem psíquica (Carvalho, 2010).

Com o intuito de se contrapor a essa visão, de que há um instinto que impulsiona todos os seres humanos a condutas universais, surge uma nova compreensão de sexualidade, que considera as experiências e os comportamentos sexuais distintos de acordo com as várias culturas. Nesta direção, a sexualidade é compreendida como um constructo histórico-social que não se restringe à função reprodutiva, envolvendo a busca pelo prazer, a qual integra aspectos das diversas dimensões do humano e influencia no modo como as pessoas se relacionam consigo e com os outros. Gênero, geração, parentesco, classe social, etnia e outras formas de estratificação social são consideradas influências importantes na formação das significações sobre a sexualidade (Araújo, 2002; Carvalho, 2010; Foucault, 1998).

Foucault, estudioso da sexualidade humana, de sua história e significados, considera que, apesar de tamanha importância, o tema "sexualidade" é ainda muito envolto por tabus e pouco explorado em nossa sociedade. A atividade sexual sempre foi objeto de preocupação moral, submetida a dispositivos de controle das práticas e comportamentos sexuais, construídos com base nos valores e ideologias predominantes na sociedade (Araújo, 2002; Foucault, 1998; Gir et al., 2000).

Rubin (1989) levantou a existência de uma hierarquia sexual, em que algumas práticas são consideradas inadequadas e desviantes. Dentre elas, estão a masturbação, sexo fora do matrimônio, promiscuidade, sexo realizado em público, prostituição, pornografia, sexo com uso de objetos fetichistas, jogos sexuais, homossexualidade, sexo sem fins de procriação, orgias, sexo entre jovens, sexo entre idosos, sexo entre enfermos e entre pessoas com incapacidades. Para Foucault (1998), a família, a igreja e a escola consolidaram essas crenças e serviram de base reguladora da sexualidade, responsabilizando-se pelo controle e normatização dos chamados "impulsos sexuais".

Os conceitos de sexualidade e práticas sexuais sofreram profundas mudanças históricas (Foucault, 1998). Dentre elas, pode-se destacar a emancipação feminina, a contracepção moderna, as novas tecnologias reprodutivas, a liberação das minorias sexuais, o sexo virtual e a mobilidade conjugal (Araújo, 2002; Carvalho, 2010; Goldenberg, 2001). Essas conquistas permitiram o surgimento de outras formas de relacionamento amoroso, no contexto heterossexual e homossexual (Furlani, 2008). No entanto, é importante destacar que conflitos e incertezas, provenientes de um choque cultural, são comuns neste contexto de contradição entre a emergência de novas configurações de relacionamentos e a manutenção de alguns valores tradicionais. O casamento formal e heterossexual, que visa a constituição da família, prioritariamente com filhos, continua sendo uma referência, mas convive com outras formas de relacionamento conjugal, como casamentos sem filhos ou sem coabitação e uniões homossexuais (Araújo, 2002).

Considera-se, então, que a sexualidade é construída sócio-historicamente e que a sua vivência é influenciada pelo gênero, raça, idade, classe social, sociedade, modo de produção e momento histórico no qual está inserido o sujeito, como também por sua singularidade, sendo a sexualidade, desta forma, única para cada indivíduo. Neste contexto de transformação da intimidade, dos valores e das formas de pensar, o que favorece a flexibilidade da sociedade a acolher novas configurações das relações amorosas (Araújo, 2002), estão inseridas as pessoas que vivem com HIV/aids. Sentimentos de angústia, tristeza e medo podem fazer parte da realidade de sua vivência sexual. Torna-se, então, um desafio para os sujeitos infectados lidar com o risco concreto da transmissão da infecção e, especialmente, com o estigma, preconceito e discriminação associados à aids. Essa problemática pode desencadear redução da libido, diminuição na frequência das relações sexuais ou até mesmo a abstinência, interferindo no exercício da sexualidade das pessoas que vivem com HIV (Carvalho, Anchieta, Queiroz, Aragão, \& Nichiata, 2013).

Quando envolvido amorosa e/ou sexualmente com alguém, há a possibilidade de o sujeito soropositivo relacionar-se com outros indivíduos na mesma condição, ou seja, soroconcordantes, ou com outros indivíduos soronegativos, ou seja, sorodiscordantes. Se a realidade de uma relação for a sorodiscordância, ou seja, apenas um é portador do HIV/aids, a sexualidade e o comportamento sexual podem ser abalados e o manejo de algumas dificuldades ligadas à intimidade dos envolvidos será necessário, principalmente no que se refere à possibilidade de transmissão do HIV para o parceiro soronegativo (Reis, \& Gir, 2010). Esta ideia é corroborada por Freitas, Gir e Fugerato (2002), ao considerar que o risco e o medo relacionado à infecção pelo vírus podem acabar afetando o exercício da sexualidade do seu portador, que, muitas vezes, chega até mesmo a interromper suas práticas sexuais após 
o diagnóstico, ou ter seu desempenho sexual prejudicado. Nesses casos, uma medida preventiva adotada pelo Ministério da Saúde do Brasil desde 2010 é a disponibilização de medicamentos antirretrovirais para parceiros sexuais soronegativos que passaram por situação de risco, como relação sexual sem proteção, ou quando ocorre rompimento do preservativo durante a relação sexual (Said, \& Seidl, 2015).

Quando há uma relação estável, outro ponto a ser considerado como dificuldade na revelação do diagnóstico é que, na representação social da soropositividade e aids, associa-se essa patologia à instabilidade em relacionamentos ou ao envolvimento do portador em relações sexuais com outros parceiros além daquele com que se mantém um relacionamento amoroso/sexual estável. Esta ideia justifica, inclusive, o não uso de medidas protetivas à transmissão do HIV e outras DSTs pela maioria dos casais quando se espera que haja fidelidade entre os parceiros. Sendo assim, a descoberta de que o parceiro tem HIV pode abalar a confiança do casal (Oltramari, \& Camargo, 2010).

Toda essa problemática torna bastante complexa a revelação do diagnóstico aos parceiros afetivos e/ ou sexuais. Por um lado, é reconhecida a necessidade de proteger o parceiro da possibilidade de contrair a infecção, por outro, revelar sua condição pode levar ao abandono por parte do outro. O resultado costuma ser deixar para mais tarde a decisão de revelar, ou não, o diagnóstico. A consequência desse impasse pode ser a transmissão desenfreada do vírus, já que o casal fica impedido de discutir abertamente os modos de se proteger (Marques et al., 2006).

Outra realidade é a parceria composta por pessoas soropositivas, ou soroconcordantes. Alguns receios podem ser diminuídos, neste caso, já que a infecção pelo HIV é uma realidade para ambos. Neste enquadre ocorre, com frequência, a crença equivocada de que se pode abrir mão do uso do preservativo, pois ambos possuem HIV. Entretanto, essa prática é considerada insegura já que expõe os parceiros à troca de diferentes tipos de vírus, podendo causar resistência aos medicamentos antirretrovirais prescritos (Silva, \& Camargo Júnior, 2011).

Com base na revisão de literatura acima, considera-se de suma importância discutir e problematizar a sexualidade do sujeito soropositivo. Com este intuito, foi desenvolvida uma pesquisa qualitativa, por uma residente de Psicologia em Infectologia, em um hospital de referência do estado de Goiás no atendimento ao portador do HIV/aids. O objetivo geral foi investigar e descrever como os sujeitos soropositivos vivenciam sua sexualidade e seus relacionamentos afetivos e/ou sexuais. Os objetivos específicos visaram investigar as principais dificuldades neste âmbito e os mecanismos de enfrentamento empregados para lidar com tais dificuldades. Como hipótese, supôs-se que o acometimento e diagnóstico do HIV/aids influenciam, negativamente, a sexualidade dos sujeitos infectados.

\section{Método}

Esta foi uma pesquisa descritiva, que investigou a vivência da sexualidade de pessoas infectadas pelo HIV, que fazem tratamento no hospital de referência, suas principais dificuldades nesse âmbito, assim como os mecanismos de enfrentamento mais empregados. Para tanto, fez-se uso do método fenomenológico, desenvolvido por Edmund Husserl, definido como um método filosófico descritivo, que se aplica à relação entre consciência e experiência, considerando que ambas são indissociáveis. Tal método não visa respostas casuais para os fenômenos, e sim compreendê-los em sua totalidade (Gomes, \& Castro, 2010).

\section{Participantes}

Os participantes deveriam se encaixar nos seguintes critérios de inclusão: serem maiores de 18 anos, terem recebido o diagnóstico de HIV, estarem em acompanhamento médico no hospital de referência, não terem nenhuma comorbidade psiquiátrica grave e desejarem participar da pesquisa. Os participantes poderiam ser de ambos os sexos, de variadas identidades de gênero, orientações e práticas sexuais, assim como estarem ou não em internação. Caso estivessem internados, não poderiam estar em regime de precaução de aerossóis, empregada para prevenir a transmissão de doenças disseminadas pelo ar, e/ou precaução de contato, que destina-se àqueles pacientes que estão acometidos por doenças transmissíveis pelo seu contato direto com outra pessoa, já que estas impediriam o deslocamento ao consultório de Psicologia, onde se deu a coleta de dados.

A amostra deu-se por conveniência, sendo os participantes definidos à medida que eram encaminhados pelos psicólogos que os atendiam. A pesquisa contou com 10 participantes, nove do sexo masculino e um do sexo feminino. Dos nove, cinco participantes se consideram homossexuais e cinco heterossexuais (incluindo a mulher). 


\section{Instrumentos}

Foi realizada com cada participante uma coleta de dados sociodemográficos e também de informações acerca de sua orientação e prática sexual, seguida por uma entrevista, guiada por um roteiro organizado em forma de checklist.

\section{Procedimentos}

Após aprovação do projeto pelo Comitê de Ética em Pesquisa do próprio hospital, solicitou-se aos psicólogos do Setor de Psicologia que encaminhassem possíveis participantes. Cada um deles passou por uma triagem com a pesquisadora, para verificar se os critérios de inclusão para participação na pesquisa eram preenchidos. Além disso, eram-lhe explicados os objetivos da pesquisa e os seus direitos como participante. Caso concordassem e assinassem o TCLE e o Termo de Pós-Esclarecimento, eram coletados dados sociodemográficos e informações acerca de sua orientação e prática sexual. Em seguida, iniciava-se com o participante uma entrevista semiestruturada. As entrevistas seguiram o tempo estimado de aproximadamente 30 minutos. Para orientar a entrevista, fez-se uso de um checklist contendo os principais pontos a serem investigados. Todas as entrevistas foram gravadas e, posteriormente, transcritas pela pesquisadora residente.

Realizou-se uma análise dos dados sociodemográficos e dados quanto à orientação e prática sexual dos sujeitos envolvidos na pesquisa, com o intuito de averiguar o perfil dos participantes deste estudo. A análise dos dados coletados nas entrevistas deu-se da seguinte forma: durante a leitura das transcrições agrupou-se as falas dos sujeitos em grupos temáticos, o que facilitou a interpretação dos dados. A partir disso, fez-se uma análise descritiva das informações obtidas, correlacionando-as com a literatura revisada sobre a temática da sexualidade de pacientes soropositivos.

\section{Discussão de resultados}

Inicialmente, considerou-se relevantes alguns dados sociodemográficos dos 10 participantes da pesquisa: oito eram homens e se intitularam do gênero masculino. Participaram, também, uma mulher, do gênero feminino, e uma transexual. Suas idades variaram de 24 a 53 anos, sendo que a maioria (sete) encontrava-se na faixa etária de 32 a 43 anos. Quanto à escolaridade, cinco participantes concluíram o Ensino Médio, dois concluíram o Ensino Superior, dois tinham
Ensino Fundamental incompleto e um tinha Ensino Fundamental completo. A maioria da amostra (sete) afirmou ser residente no interior de Goiás. Os três que alegaram residir em Goiânia, são das regiões central, leste e norte. Apenas um participante tinha diagnóstico de transtorno psiquiátrico: retardo mental leve.

No decorrer da entrevista, quatro homens afirmaram ser homossexuais e quatro afirmaram ser heterossexuais. A mulher e a transexual definiram-se como heterossexuais. Dos quatro homens de orientação homossexual, três têm prática sexual apenas com homens e um tem prática sexual também com mulheres, apesar da preferência pelo mesmo sexo.

\section{Vivência da Sexualidade}

Aspectos positivos e negativos dos relacionamentos afetivos e sexuais

Os sujeitos entrevistados citaram algumas vantagens ou aspectos positivos de se manter um relacionamento afetivo: carinho; atenção; melhorias pessoais; melhora do humor; ter alguém com quem contar; segurança; cumplicidade; parceria; reciprocidade.

Quatro participantes citaram companheirismo e três citaram companhia. Quando questionados sobre as desvantagens ou pontos negativos de se manter um relacionamento afetivo mencionaram: falsidade; brigas; ciúmes; falta de reciprocidade; intensidade do sentimento por parte de apenas uma pessoa no relacionamento; traição. Duas pessoas disseram que a mentira é um dos lados negativos dos relacionamentos afetivos e duas referiram que o possível sofrimento é o maior complicador.

Ao serem questionados sobre as vantagens ou aspectos positivos de se manter um relacionamento sexual, três sujeitos alegaram que a maior delas é o prazer. Também foram citados: melhoria da sexualidade (aqui tida como prática sexual); o outro saber a sua vontade e desejos; sentir-se bem; ter alguém; facilidade de se entregar em relacionamentos.

O participante 3 ( $\mathrm{P} 3$ - homem, heterossexual) falou sobre como pode ser positiva a relação sexual com parceira fixa e aborda a temática do HIV e o risco de contaminação por doenças oportunistas, implicitamente:

Por que que é bom ter um relacionamento sexual? (Pesquisadora).

[...] Você já tem sua parceira ali. Cê já conhece ela, cê sabe que ela não tem doença oportunista, não tem outra coisa (P3). 
Quanto às desvantagens ou pontos negativos de se manter um relacionamento sexual, alguns participantes mencionaram: doenças e falta de confiança. Promiscuidade apareceu no discurso de dois sujeitos.

Percebe-se a partir dos discursos dos sujeitos entrevistados que as vantagens em ter um relacionamento afetivo mais citadas são companhia e reciprocidade e que a busca pelo prazer é a motivação para se envolver sexualmente com alguém mais mencionada pelos entrevistados. São impasses comuns nos relacionamentos afetivos a mentira e a possibilidade de sofrimento; já doenças e falta de confiança são aspectos que diminuem o interesse da maior parte dos participantes.

Relacionamentos afetivos e sexuais antes e depois do diagnóstico

Um aspecto importante abordado na pesquisa foi a existência de relacionamentos afetivos e/ou sexuais atualmente. A maioria dos participantes (sete) não mantém, no momento, relacionamento afetivo e nem sexual (seis), o que foi relacionado, por eles, ao diagnóstico de HIV. Esta relação pode ser exemplificada por um trecho da entrevista de um dos participantes:

[...] Primeiro eu quero saber se você tem alguém nesse momento que você está se relacionando afetivamente (Pesquisadora).

Desde quando eu descobri que eu contraí o HIV, nunca mais eu tive... (P8-mulher, heterossexual).

A realidade dos participantes corrobora com a literatura acerca das dificuldades daqueles que convivem com o HIV em manter um relacionamento, já que podem acarretar sentimentos de angústia, tristeza e medo, muitas vezes ligados ao estigma, preconceito e discriminação associados à aids. Esta vivência acaba por interferir fortemente na vivência da sexualidade destes sujeitos, que, com o tempo, podem ter a frequência de seus relacionamentos reduzida (Carvalho et al., 2013; Freitas et al., 2002).

A maioria (oito) dos participantes sempre que se envolve com alguém, mantém relação sexual. Essa não é a realidade quando se fala de envolvimento afetivo com os(as) parceiros(as): apenas quatro participantes afirmaram sempre ter afeto envolvido em seus relacionamentos e cinco alegaram que apenas alguns envolvem afeto. Estes dados vão em direção contrária à afirmação de Pais (1996), de que existe uma tendência em nossa sociedade a associarmos em nossos relacionamentos amor e sexo.
Envolver-se afetivamente pode significar maior necessidade em manejar e compartilhar o diagnóstico de HIV/aids, o que pode levar à perda do parceiro, tanto pelo adoecimento, como pelos conflitos, mágoas ou ressentimentos que podem estar envolvidos na aquisição do vírus (Reis et al., 2011).

Quando questionados sobre como eram seus relacionamentos antes e depois do HIV, três participantes envolviam-se sexualmente com vários parceiros antes do diagnóstico e evitavam envolver-se afetivamente. Três participantes estavam em relacionamentos estáveis quando descobriram o HIV, sendo que destes, dois relataram infidelidade por um dos lados do casal.

Dois participantes queixaram-se de que, depois de receber o diagnóstico e revelarem ao parceiro, sofreram com baixa autoestima, colocando-se passivamente no relacionamento e deixando que apenas o parceiro tivesse voz. Isso aconteceu tanto devido à autopercepção de menos-valia, em consequência da soropositividade, como é o caso do P3 - homem, heterossexual - como por uma desvalorização do companheiro por este ter HIV, como relata o P6 - homem, homossexual. Essa problemática pode ser ilustrada pelas falas abaixo:

[...] Ter alguém, nos dois aspectos, hoje em dia, você dá mais importância do que antes do HIV? (Pesquisadora).

[...] você tem tanto medo de não conseguir outra pessoa porque você tem o HIV, aí você aceita tudo (P3).

Mas com esses parceiros seus, como que você já viveu o preconceito, como é que você já sofreu o preconceito com eles? (Pesquisadora).

O último, por exemplo, me diminuía, de certa forma. Pra ele, ele ta comigo era uma garantia pra mim, não pra ele. Com ele, eu estaria ganhando, não ele. Se ele terminasse comigo, eu estaria perdendo, não ele [...] Então, era muito difícil, foi muito difícil isso (P6).

Dois participantes relataram que após o diagnóstico de HIV iniciaram relacionamento estável e, após compartilharem sua condição sorológica, os companheiros os abandonaram. Outros dois participantes expressaram receio em transmitir o vírus para seus parceiros, o que foi um dificultador nos seus relacionamentos depois do diagnóstico de HIV. O P2 - homem, homossexual - contou que antes da soropositividade era mais confiante e tinha uma sexualidade mais ativa 
e o P10 - homem, homossexual - descreveu como se sentia em seus relacionamentos depois do diagnóstico:

E como é que é? Você percebe que tem diferença? Me conta um pouquinho dessas duas situações [...] (Pesquisadora).

A gente tinha uma sexualidade mais ativa pelo fato de que parece que tava mais confiante em si próprio [...] porque eu não tenho nada pra mim transmitir (P2).

Só que o senhor me falou lá atrás que o senhor acredita que é muito assim, de não se envolver tanto, para não cair no risco de não ter cuidados e acabar transmitindo. Então eu vi uma relação aí com o HIV. Me explica melhor (Pesquisadora). Depois do HIV - automaticamente você pensa "nossa, eu tenho que tomar esse cuidado, aquele tipo, mais aquele, pra outra pessoa não sair, não sair perdendo no final das contas", né? (P10).

Outra participante ( $\mathrm{P} 8$ - mulher, heterossexual) nos relatou que estava em seu segundo casamento ao descobrir que era soropositiva. Acredita que adquiriu o vírus devido à infidelidade do marido. Quando the revelou, ele ficou bastante agressivo. Ao fazer o teste, seu esposo soube que também convivia com o HIV. A P8 separou-se do marido e não teve outros relacionamentos.

Um dos sujeitos (P9 - homem, homossexual) era casado com uma pessoa do sexo oposto e mantinha relações sexuais homossexuais. Desconfiou que poderia estar infectado e fez o teste, que deu positivo. Manteve-se abstêmio sexualmente em seu casamento até separar-se. Teve alguns relacionamentos estritamente sexuais após a separação e atualmente mantém relacionamento homossexual estável com parceiro soronegativo.

O P5 - mulher transexual, heterossexual - nos contou que se envolveu com várias pessoas afetivamente e sexualmente antes do diagnóstico. Acredita que, fora a prevenção durante a relação sexual, não houve mudanças nos relacionamentos. O P1 - homem, heterossexual - teve vários relacionamentos conturbados antes do diagnóstico e dois relacionamentos estáveis depois do diagnóstico, sendo um deles com uma pessoa soropositiva.

Podemos observar pelas falas dos sujeitos que todos os participantes mantinham vida sexual ativa. Alguns envolviam-se sexualmente com várias pessoas, evitando envolver-se afetivamente e manter relacionamentos estáveis. Outros estavam, no momento do diagnóstico, em um relacionamento duradouro, porém envolto por infidelidade.

O medo de transmitir o vírus e o sentimento de menos-valia, consequência de uma baixa autoestima e de um menosprezo pelo parceiro, parecem ser dificuldades comuns encontradas nos relacionamentos posteriores ao diagnóstico de HIV. Esses dados corroboram a afirmação de Reis et al. (2011), de que o diagnóstico de infecção pelo HIV modifica as expectativas do sujeito em relação a si próprio e ao meio em que vive, repercutindo no âmbito pessoal e social, podendo deteriorar as relações interpessoais e a autoestima.

Importância da vida afetiva e sexual antes e depois do diagnóstico

Fica claro o impacto do HIV na vivência da sexualidade, quando os sujeitos são solicitados a comparar a importância da vida afetiva e sexual antes e depois do diagnóstico. Para a maioria (sete), a vida afetiva perdeu importância após o diagnóstico. Para apenas um participante a infecção pelo HIV não foi responsável por nenhuma mudança neste âmbito. Para outro, o diagnóstico levou a um aumento da importância da vida afetiva. Um dos sujeitos não soube responder. Duas pessoas conferiram à vida afetiva atual nenhuma importância ou importância "zero".

Quando comparada a importância da vida sexual antes e depois do diagnóstico de HIV, para a uma maioria expressiva dos entrevistados (nove) a vida sexual também perdeu importância, como pode ser observado na fala a seguir:

Você acha que a vida sexual ficou menos importante? (Pesquisadora).

Menos. Porque depois do HIV, você passa a ver a vida sexual diferente. Você tem medo de pegar novas doenças, você tem medo de transmitir (P9 - homem, homossexual).

Apenas um participante relatou que a importância da vida sexual aumentou. Para metade dos sujeitos (cinco) a vida sexual não tem nenhuma importância hoje em dia:

Tá certo. Quais são os aspectos positivos que você vê em ter um relacionamento afetivo? Amoroso, que envolve sentimento (Pesquisadora).

[...] Eu já evito ter esse relacionamento com pessoas, pra não ter que passar por isso. [...] Zero. Não tem desejo (P6 - homem, homossexual). 
E qual que é a importância que o senhor dá para sua vida afetiva hoje em dia? (Pesquisadora).

[...] Nem penso nisso mais (P10 - homem, homossexual).

É comum pessoas que são diagnosticadas com HIV ficarem muito impactadas com o diagnóstico e o associarem diretamente, inclusive, com o fim da vida. Torna-se um desafio elaborar e enfrentar a nova realidade e as dificuldades sociais e emocionais que tendem a surgir. Junto a elas, vários são os impasses no campo da sexualidade (Freitas et al., 2002). Pode-se observar que conviver com o HIV não é tarefa fácil, principalmente quando além da pessoa soropositiva, exista o envolvimento de um outro sujeito. Isto pode levar à diminuição da importância da sexualidade para os sujeitos infectados, como é observado a partir da fala dos participantes, que, em sua maioria, tiveram o interesse por sua vida afetiva e sexual diminuída após a descoberta do diagnóstico de HIV.

É possível, também, que haja um deslocamento de investimento de energia dos sujeitos soropositivos para outros campos da vida, como estudos e saúde, que foram apontados por dois participantes como foco de interesse no momento. Isto pode ser visto pela fala do P7 (homem, heterossexual), que vem dando maior prioridade à sua saúde, em comparação à sua sexualidade:

[...] E antes do HIV, qual importância que você dava para sua vida afetiva e para sua vida sexual? (Pesquisadora).

De uns tempos pra cá praticamente eu tô vivendo no hospital e na casa de apoio (P7).

Este exemplo corrobora com a ideia de Reis et al. (2011) de que a cronicidade da patologia repercute no âmbito pessoal e social, tornando necessárias mudanças no estilo de vida, que envolvem a adaptação ao tratamento.

\section{Dificuldades nos relacionamentos afetivos e sexuais}

Principais dificuldades

Um dos aspectos cruciais da pesquisa foi a investigação das principais dificuldades vivenciadas pelos participantes em seus relacionamentos durante a vida. As dificuldades apontadas em geral foram: impotência sexual; ansiedade; humor rebaixado; oscilação do humor; conflitos diversos; ser homossexual e manter relação sexual com pessoas do sexo oposto; postura arrogante; diferença de classe social/escolaridade do(a) parceiro(a); agressividade; agressividade do(a) parceiro(a); abuso de álcool do(a) parceiro(a); mentira do(a) parceiro(a); os dois terem "gênios" parecidos; características "específicas do mundo gay" como infidelidade e falta de confiança. Traição foi citada por duas pessoas como grande dificuldade nos relacionamentos vividos.

A aids é comumente associada à instabilidade em relacionamentos ou ao envolvimento do portador em relações sexuais com outros parceiros além daquele com que mantém um relacionamento amoroso/sexual estável. Sendo assim, a descoberta de que o parceiro tem HIV pode abalar a confiança do casal (Oltramari, \& Camargo, 2010).

Dificuldades relacionadas ao HIV

Em relação às dificuldades em relacionamentos afetivos e/ou sexuais, relacionadas à condição de soropositividade e ao HIV, foram relatadas pelos participantes: possibilidade de ter doenças que incapacitam para o trabalho, o que prejudica no provimento de uma família; medo de ser exposto socialmente; e o(a) parceiro(a) querer ter relacionamento sexual sem preservativo.

Quatro participantes acreditam que o preconceito e a discriminação, advindos da condição de soropositividade, são grandes dificuldades, confirmando as afirmações de Gaspar et al. (2011) e Gomes et al. (2011), acerca do medo em ser julgado. Esse receio leva até mesmo à ocultação do diagnóstico como estratégia para minimizar seu impacto social. Podemos entender melhor este conflito a partir dos relatos abaixo:

[...] Você percebe que teve alguma dificuldade nos seus relacionamentos afetivos por causa do HIV, do diagnóstico? (Pesquisadora).

[...] a maioria das pessoas, se ficar sabendo que você tem o problema, o vírus, logicamente vai ter preconceito (P1 - homem, heterossexual).

Eles te olhavam, te viam como uma pessoa diferente? Diferente como? (Pesquisadora).

[...] O preconceito, né? "nossa, o que minha filha tá fazendo com esse cara? Ele não vai acrescentar nada pra vida dela" (P3 - homem, heterossexual). 
Corroborando com a ideia de Carvalho et al. (2013), que apontam como dificuldade importante o medo de transmitir o HIV ao parceiro, três participantes alegam ser esse um dos seus principais desafios, como é ilustrado pela fala do participante 10 (homem, homossexual):

[...] Em que sentido o senhor procura se resguardar? (Pesquisadora).

[...] Prefiro não me envolver muito pra não ter chances de ter mais facilidade de passar alguma coisa pra alguém (P10).

Duas pessoas mencionaram rebaixamento do desejo sexual causado pela TARV. Outros dois sujeitos trouxeram como dificuldade o afastamento e a rejeição de parceiros(as), como cita P2 (homem, homossexual):

Você consegue perceber, você acha que o HIV trouxe alguma dificuldade para sua vida afetiva, para sua vida sexual? (Pesquisadora).

[...] Elas se afastam de você, pelo fato de você ser soropositivo (P2).

A literatura também aponta que os sujeitos soropositivos sofrem com o risco da transmissão do HIV e, especialmente, com o estigma, preconceito e discriminação associados à aids, o que muitas vezes leva à redução da libido, diminuição na frequência das relações sexuais ou até mesmo a abstinência sexual (Carvalho et al., 2013). Como pode-se ver, esse dado foi confirmado pelos participantes da pesquisa.

\section{Soroconcordância e sorodivergência}

Ao investigar quanto à sorologia dos parceiros dos sujeitos entrevistados, percebeu-se que a vivência da soroconcordância tende a ser diferente da sorodiscordância, sendo que a segunda é vista por si só como uma dificuldade no campo da sexualidade dos participantes.

Metade dos participantes (cinco) relataram manter relacionamentos com pessoas soronegativas ou cuja sorologia desconhecem. A outra metade (cinco) mantém relacionamentos tanto com pessoas soropositivas como com pessoas soronegativas.

Observou-se que os sujeitos entrevistados percebem a vivência da soroconcordância como mais tranquila do que da sorodivergência, principalmente devido ao receio em transmitir o vírus na segunda situação. Podemos exemplificar esta percepção com os seguintes trechos:

E a segunda, que era soropositiva? (Pesquisadora). Essa era mais tranquilo ainda (P1 - homem, heterossexual).

E como é que é essa experiência de ficar com quem tem e ficar com quem não tem? (Pesquisadora).

[...] Uai, cê ficar com quem tem, eu acho assim, eu me sinto mais tranquilo, pra falar a verdade. [...] Dá, porque o seguinte, a pessoa sempre tem o HIV, se por acaso estourar uma camisinha, se caso acontecer outra coisa, eu sei que não vou tá passando aquele problema meu pra ela, que ela já tem. Às vezes, pode piorar mais um pouquinho, pra ela como pra mim. Agora, a pessoa que não tem, já tem mais cuidado, já é mais sensível, entendeu? Cê já fica com aquele pensamento "Nossa Senhora! Se acontecer alguma coisa aqui, eu acabo com a vida dessa pessoa". [...] Cê fica inseguro, tal, sobre a pessoa. Cê fica com medo, "nossa, e se ela descobrir e tal...” [...] Que quando a pessoa descobre, ela muda o jeito com você. Não tem jeito de não mudar (P7-homem, heterossexual).

Como é que você sentia com o "liberar geral" ou com o "não liberar geral"? (Pesquisadora).

$\mathrm{O}$ "liberar geral" é muito melhor (P9 - homem, homossexual).

Já com relação à revelação ao parceiro de sua condição de soropositividade, a maioria da amostra (oito) afirmou que sempre informa ao parceiro o diagnóstico de HIV e que percebe a não revelação como uma atitude covarde, com intenção de prejudicar o outro, como expressa o participante $\mathrm{P} 4$ (homem, heterossexual):

Sempre você fala? (Pesquisadora).

Eu não sou covarde [...] Tem hora que eu penso "não, vou esperar um tempo pra ver se é melhor" [...] Eu tenho medo de não falar, também, e depois ela falar que fui covarde com ela (P4).

A partir destes trechos acima, percebe-se que a vivência da sorodivergência tende a ser mais complicada, insegura, temerosa e cheia de fantasias, principalmente no que se refere ao medo de transmitir e ao medo do julgamento do outro quando revelada a soro- 
logia. Em contrapartida, o relacionamento soroconvergente é tido como mais "tranquilo", já que o dispêndio de energia com a preocupação de transmissão é menor.

Supõe-se que essa diferença na vivência da soroconcordância e sorodivergência se deve em muito à crença equivocada de que quando a parceria é composta de duas pessoas soropositivas pode-se abrir mão do uso do preservativo, pois ambos possuem HIV e não há, então, o risco de transmissão. Entretanto, essa prática é considerada insegura já que expõe os parceiros à troca de diferentes tipos de vírus, podendo causar resistência à TARV, além de expô-los a outras doenças sexualmente transmissíveis (Silva, \& Camargo Júnior, 2011). Nas entrevistas, toda vez que essa temática surgiu, foi seguida por fala que revelava compreensão adequada acerca dos riscos de transmissão e troca viral em relacionamentos soroconvergentes, o que nos leva a crer que os pacientes da instituição estão recebendo orientações da equipe de saúde neste sentido. Todos os participantes que salientavam esta compreensão correta eram reforçados positivamente, assim como era fortalecida a importância do uso dos preservativos em todas as relações sexuais, independentemente do status sorológico do parceiro.

\section{Mecanismos de Enfrentamento}

Principais mecanismos de enfrentamento

Como mecanismos de enfrentamento às dificuldades nos relacionamentos em geral foram citados alguns focalizados no problema, ou seja, na resolução da situação estressora e outros focalizados na emoção ou manejo dos sentimentos (Carvalho, 2009). Os primeiros resumiram-se em uma reestruturação cognitiva ou mudança de foco como: pensar coisas boas; evitar pensar na dificuldade; trabalhar. Já os mecanismos de enfrentamento mencionados focalizados na emoção citados foram: controlar o desejo sexual, não enfrentar e negar.

Além destes mecanismos de enfrentamento às dificuldades nos relacionamentos citados acima, um dos participantes surpreendeu-nos expondo o uso de álcool como uma forma de lidar melhor com os problemas. Moura, Braga, Leite, Silva e Leite (2013) perceberam que uma das grandes motivações para fazer o uso do álcool, em adultos, é fugir dos problemas e das situações estressantes do cotidiano, já que o álcool pode oferecer, temporariamente, a sensação de relaxa- mento. Este participante recebeu a orientação de procurar a ajuda de um profissional e iniciar psicoterapia.

Mecanismos de enfrentamento às dificuldades relacionadas ao HIV

No que se refere aos mecanismos de enfrentamento para as dificuldades nos relacionamentos advindas da condição de soropositividade foram mencionados por dois participantes distintos: evitar relacionamento; evitar relações sexuais; amizades e família; e não fazer nada. Percebe-se que há prevalência dos mecanismos de enfrentamento focalizados no problema, evitando relacionamentos, ou contando com a rede de apoio social.

Outros mecanismos citados uma vez foram: religiosidade/religião; tentar ignorar as dificuldades; negar o diagnóstico aos outros quando questionado(a) sobre sua sorologia; obter mais informações com a equipe médica para tirar as dúvidas do(a) parceiro(a); empoderar-se; não abrir mão do uso de camisinha mesmo quando solicitado pelo(a) parceiro(a); participar de reuniões e atendimentos do Setor de Adesão do hospital.

Muitas destas formas de enfrentamento, como evitar envolver-se ou esconder o diagnóstico, devem-se ao conflito de que, se por um lado é reconhecida a necessidade de proteger o parceiro da possibilidade de contrair a infecção, por outro, revelar sua condição pode levar ao abandono por parte do outro (Marques et al., 2006), o que foi corroborado pelos participantes do estudo.

\section{Considerações finais}

Os resultados apontam para experiências diversas de pessoas com HIV. Percebeu-se que os modos de enfrentamento do sofrimento e das dificuldades dos participantes deste estudo, diante do impacto do diagnóstico e da vivência da soropositividade, vão ao encontro da literatura da área. Diante da cronicidade da aids e da maior sobrevida das pessoas que vivem com HIV, pode-se dizer que estes sujeitos possuem experiências significativas em relação à vida amorosa e à sexualidade, confirmando a relevância deste trabalho, que trata de um assunto atual e socialmente significativo.

Percebeu-se que os nossos participantes enxergam vantagens em se ter um relacionamento afetivo, principalmente pela companhia e reciprocidade, assim como o prazer é a principal motivação para se envolver sexualmente com alguém. Entretanto, a mentira, a pos- 
sibilidade de sofrimento, o risco de adquirir DSTs e falta de confiança são empecilhos para a maioria dos participantes se relacionarem com alguém. Somado a isso, existe o medo de transmitir o vírus e de ser menosprezado ou abandonado pelo parceiro, principalmente se este não é também soropositivo. Sendo assim, grande parte dos sujeitos evitam envolver-se sexualmente e amorosamente com outra pessoa.

As principais dificuldades vivenciadas pelos sujeitos entrevistados são o preconceito e a discriminação, advindos da condição de soropositividade, juntamente com o medo de transmitir o HIV ao parceiro e o rebaixamento do desejo sexual causado pela TARV. Diante destas dificuldades, os nossos participantes optam por revelar o diagnóstico, mesmo que isto lhe custe seu relacionamento, já que a não revelação é percebida como atitude covarde e prejudicial ao outro. Entretanto, esta não é uma tarefa fácil e torna os relacionamentos sorodivergentes mais difíceis para os sujeitos que convivem com o HIV.

Como mecanismos de enfrentamento a essas dificuldades destacam-se, por um lado, a fuga de sentimentos e pensamentos e, por outro, a busca por apoio na família, rede de amigos, religiosidade e a instituição de saúde. Entretanto, se pudessem escolher, voltariam atrás no momento em que se infectaram pelo vírus, fariam outras escolhas e correriam menos riscos. Infelizmente, essa não é uma possibilidade para o sujeito soropositivo. Resta-lhe esperar e crer em uma cura e enquanto ela não vem, cabe-lhes manejar todas as perdas que lhes são impostas a partir do teste positivo para HIV, deixando muitas vezes de lado o amor e o prazer, que agora é risco de vida para o outro.

Foi oferecida aos participantes a oportunidade de se expressarem quanto ao desejo de mudança em seus relacionamentos afetivos/sexuais. A partir de suas respostas, percebe-se que os sujeitos gostariam de: retornar à capacidade sexual anterior; ser mais carinhosos; ser mais prestativos; ser mais compreensivos; ter relacionamentos que envolvem tanto o amor quanto a química; voltar no passado com a "cabeça que tem hoje”; não se entregar tão fácil; modificar o receio que o parceiro tem de fazer o teste de HIV; ter alguém em que possa mandar; ter se prevenido:

Se você pudesse mudar alguma coisa nos seus relacionamentos afetivos, sexuais, dos que se passaram, o que você mudaria? (Pesquisadora). [...] Eu teria me prevenido [...] Pra não ter pego o HIV. Eu acho que essa era a parte que seria crucial na minha vida (P8 - mulher, heterossexual).

Cabe lembrar que a maior parte dos participantes estavam em contexto de internação hospitalar, devido à recente descoberta do diagnóstico, não adesão ao tratamento ou adoecimento por outras causas. Dessa forma, este estudo não abordou a temática da sexualidade do sujeito que vive com HIV/aids sob uma perspectiva mais positiva, já que partiu da entrevista com pessoas, em sua maioria, em situação de adoecimento. Como limitação deste estudo identificou-se a dificuldade em buscar pacientes que se adequassem ao critério de inclusão de não estarem internados em algum regime de precaução, já que a instituição de referência acolhe pacientes com as mais diversas patologias infecciosas, a maioria delas transmissíveis, o que impossibilitava o paciente adentrar o local de entrevista. Sugere-se que novas pesquisas sejam realizadas abordando e investigando a temática da sexualidade do sujeito que vive com HIV/aids, já que esta tende a ser permeada por grande sofrimento psíquico, que precisa ser melhor acolhido, compreendido e ressignificado.

\section{Referências}

Araújo, M. F. (2002). Amor, casamento e sexualidade: velhas e novas configurações. Psicologia: Ciência e Profissão, 22(2), 70-77. https://doi.org/10.1590/S1414-98932002000200009

Ayres, J. R. C. M., Calazans, G. J., Saletti Filho, H. C., \& França-Júnior, I. (2006). O risco, vulnerabilidade e práticas de prevenção e promoção da saúde. Recuperado de https://edisciplinas.usp.br/pluginfile.php/347426/mod_ resource/content/1/risco_vulnearabilidade\%20Ayres\%20e\%20cols.pdf

Brasil. (2002a). Ministério da Saúde. AIDS: Etiologia, clínica, diagnóstico e tratamento. Brasília, DF: o autor.

Brasil. (2002b). Ministério da Saúde. Protocolo clínico e diretrizes terapêuticas para

adultos vivendo com HIVIAids. Brasília, DF: o autor. 
Brasil. (2015). Portal sobre aids, doenças sexualmente transmissiveis e hepatites virais. Recuperado de http://www. aids.gov.br/

Carvalho, E. S. S. (2010). Viver a sexualidade com o corpo ferido: representações de mulheres e homens (doutorado). Universidade Federal da Bahia, Salvador, BA, Brasil.

Carvalho, F. T. (2009). Contribuições de uma intervenção psico-educativa para as estratégias de enfrentamento e a qualidade de vida de gestantes portadoras de HIVIAIDS (doutorado). Programa de Pós-graduação em Psicologia, Universidade Federal do Rio Grande do Sul, Porto Alegre, RS, Brasil.

Carvalho, P. M. G., Anchieta, L. S., Queiroz, M. M., Aragão, A. O., \& Nichiata, L. Y. I. (2013). Sexualidade de pessoas vivendo com HIV/AIDS. Revista Interdisciplinar, 6(3), 81-88.

Foucault, M. (1988). História da sexualidade: A vontade de saber. Rio de Janeiro, RJ: Graal.

Freitas, M. R. I., Gir, E., Fugerato, A. R. F. (2002). Sexualidade do portador do vírus da imunodeficiência humana (HIV): Um estudo com base na teoria da crise. Revista Latino-Americana de Enfermagem, 10(1), 70-76. https:// doi.org/10.1590/S0104-11692002000100011

Furlani, J. (2008). Mulheres só fazem amor com homens? A educação sexual e os relacionamentos entre pessoas do mesmo sexo. Pro-Posições, 19(2), 111-131. https://doi.org/10.1590/S0103-73072008000200009

Gaspar, J., Reis, R. K, Pereira, F. M. V., Neves, L. A. S., Castrighini, C. C., \& Gir, E. (2011). Qualidade de vida de mulheres vivendo com o HIV/Aids de um município do interior paulista. Revista da Escola de Enfermagem da USP, 45(1), 230-236. https://doi.org/10.1590/S0080-62342011000100032

Gir, E., Nogueira, M. S., \& Pelá, N. T. R. (2000). Sexualidade humana na formação do enfermeiro. Revista Latino-Americana de Enfermagem, 8(2), 33-40. https://doi.org/10.1590/S0104-11692000000200006

Goldenberg, M. (2001). Sobre a invenção do casal. Estudos e Pesquisas em Psicologia, 1(1), 46-53.

Gomes, W. B., \& Castro, T. G. (2010). Clínica fenomenológica: do método de pesquisa para a prática psicoterapêutica. Psicologia: Teoria e Pesquisa, 26(no spe), 81-93. https://doi.org/10.1590/S0102-37722010000500007

Gomes, A. M. T., Silva, E. M. P., \& Oliveira, D. C. (2011). Representações sociais da AIDS para pessoas que vivem com HIV e suas interfaces cotidianas. Revista Latino-Americana de Enfermagem, 19(3), 485-492. https://doi. org/10.1590/S0104-11692011000300006

Lazarus, R. S., \& Folkman, S. (1984). Stress, appraisal, and coping. New York, NY: Springer.

Marques, H. H. S., Silva, N. G., Gutierrez, P. L., Lacerda, R., Ayres, J. R. C. M., Negra, M. D. et al. (2006). A revelação do diagnóstico na perspectiva dos adolescentes vivendo com HIVIAIDS e seus pais e cuidadores. Cadernos de Saúde Pública, 22(3), 619-629. https://doi.org/10.1590/S0102-311X2006000300017

Moura, M. A. P., Braga, J. L. B., Leite, E. S., Silva, J. G., \& Leite, J. S. (2013). Motivação para o consumo de álcool entre adultos jovens em Teresina. Revista Interdisciplinar, 6(1), 62-70.

Oltramari, L. C., \& Camargo, B. V. (2010). Aids, relações conjugais e confiança: um estudo sobre representações sociais. Psicologia em Estudo, 15(2), 275-83.

Onusida. (2004). Viver num mundo confrontando o VIH e à SIDA: Informação destinada a funcionários do sistema das Nações Unidas e suas famílias. Genebra: o autor.

Onusida. (2016). Banco de dados: Epidemiologia. Genebra: o autor. Recuperado de http://www.unaids.org/es

Pais, J. M. (1996, março). Vivências sexuais: Modos e diversidades. Actas do Congresso de Sociologia, Lisboa, Portugal, 3.

Portal da Juventude. (2015). Saúde e Sexualidade infantil. A fisiologia da sexualidade. Lisboa: o autor. Recuperado de http://juventude.gov.pt/SaudeSexualidadeJuvenil/Sexualidade/NossoCorpo/Paginas/Afisiologiadasexualidade.aspx

Reis, R. K., \& Gir, E. (2010). Convivendo com a diferença: o impacto da sorodiscordância na vida afetivo-sexual de portadores do HIV/AIDS. Revista da Escola de Enfermagem da USP, 44(3), 759-765. https://doi.org/10.1590/ S0080-62342010000300030

Reis, R. K., Santos, C. B., Dantas, R. A. S., \& Gir, E. (2011). Qualidade de vida, aspectos sociodemográficos e de sexualidade de pessoas vivendo com HIV/AIDS. Texto \& Contexto - Enfermagem, 20(3), 565-575. https://doi. org/10.1590/S0104-07072011000300019 
Rubin, G. (1989). Reflexionando sobre el sexo: Notas para una teoría radical de La sexualidad. In: Vance, C. Explorando la sexualidad femenina (pp. 113-190). Madrid: Revolución.

Said, A., \& Seidl, E. M. F. (2015). Sorodiscordância e prevenção do HIV: percepções de pessoas em relacionamentos estáveis e não estáveis. Interface (Botucatu), 19(54), 467-478. https:/ /doi.org/10.1590/1807-57622014.0120

Silva, A. M., \& Camargo Júnior, K. R. (2011). A invisibilidade da sorodiscordância na atenção às pessoas com HIV/ AIDS. Ciência \& Saúde Coletiva, 16(12), 4865-4874. https://doi.org/10.1590/S1413-81232011001300035

Amanda Araújo Malta de Sá

Psicóloga do Hospital Estadual de Urgências da Região Noroeste de Goiânia Governador Otávio Lage de Siqueira (HUGOL), Goiânia - GO. Brasil.

E-mail: amandamaltasa@hotmail.com"

\section{Cristina Vianna Moreira dos Santos}

Professora Adjunto do Curso de Psicologia da Universidade Federal do Tocantins (UFT), Tocantins - TO. Brasil. Coordenadora do Centro de Estudos e Práticas em Psicologia da UFT (CEPSI/ UFT). Vice-Líder do Núcleo de Estudos, Pesquisas e Extensão em Sexualidade, Corporalidades e Direitos da UFT.

E-mail: cristina.vianna@uft.edu.br

Endereço para envio de correspondência:

Avenida Lourdes Solino, Setor Universitário, CEP: 77650-000. Miracema do Tocantins - TO, Brasil.

Rua T 28, nº 1075, Setor Bueno, CEP 74210-040. Goiânia - GO, Brasil.”

Recebido 24/02/2017

Reformulado 12/09/2017

Aprovado 15/01/2018

Received 02/24/2017

Reformulated $09 / 12 / 2017$

Approved 01/15/2018

Recibido 24/02/2017

Reformulado 12/09/2017

Aceptado 15/01/2018

Como citar: Sá, A. A. M e Santos, C. V.M. (2018). A vivência da sexualidade de pessoas que vivem com HIV/Aids. Psicologia: Ciência e Profissão, 38(4), 773-786. https://doi.org/10.1590/1982-3703000622017

How to cite: Sá, A. A. M. e Santos, C. V. M. (2018). Sexual experience of people living with HIV/AIDS. Psicologia: Ciência e Profissão, 38(4), 773-786. https://doi.org/10.1590/1982-3703000622017

Cómo citar: Sá, A. A. M. e Santos, C. V. M. (2018). La vivencia de la sexualidad de las personas que viven con el VIH/SIDA. Psicologia: Ciência e Profissão, 38(4), 773-786. https://doi.org/10.1590/1982-3703000622017" 